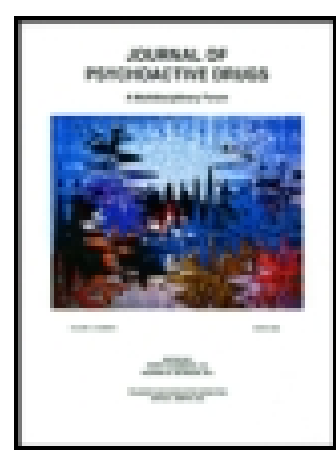

\title{
Journal of Psychoactive Drugs
}

\section{Effects of Ayahuasca and its Alkaloids on Drug Dependence: A Systematic Literature Review of Quantitative Studies in Animals and Humans}

Amanda A. Nunes B.Sc., Rafael G. dos Santos Ph.D., Flávia L. Osório Ph.D., Rafael F. Sanches Ph.D., José Alexandre S. Crippa Ph.D. \& Jaime E. C. Hallak Ph.D.

To cite this article: Amanda A. Nunes B.Sc., Rafael G. dos Santos Ph.D., Flávia L. Osório Ph.D., Rafael F. Sanches Ph.D., José Alexandre S. Crippa Ph.D. \& Jaime E. C. Hallak Ph.D. (2016): Effects of Ayahuasca and its Alkaloids on Drug Dependence: A Systematic Literature Review of Quantitative Studies in Animals and Humans, Journal of Psychoactive Drugs, DOI: $\underline{10.1080 / 02791072.2016 .1188225}$

To link to this article: http://dx.doi.org/10.1080/02791072.2016.1188225

\section{Published online: 26 May 2016.}

Submit your article to this journal $\sqsubset$

View related articles $\longleftarrow$

View Crossmark data ¿ 


\title{
Effects of Ayahuasca and its Alkaloids on Drug Dependence: A Systematic Literature Review of Quantitative Studies in Animals and Humans
}

\author{
Amanda A. Nunes, B.Sc. ${ }^{a}$, Rafael G. dos Santos, Ph.D. (1) b,c, Flávia L. Osório, Ph.D. de, Rafael F. Sanches, Ph.D.f, \\ José Alexandre S. Crippa, Ph.D., h, and Jaime E. C. Hallak, Ph.D.g,h

\begin{abstract}
${ }^{a}$ Researcher, Institute of Biosciences, University Estadual Paulista "Júlio de Mesquita Filho," Botucatu, Brazil; 'Postdoctoral Fellow, Department of Neurosciences and Behavior, Ribeirão Preto Medical School, University of São Paulo, Ribeirão Preto, Brazil; 'Advisory Board,

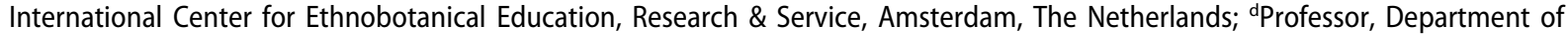
Neurosciences and Behavior, Ribeirão Preto Medical School, University of São Paulo, Ribeirão Preto, Brazil; eResearcher, National Institute of Science and Technology-Translational Medicine, Ribeirão Preto, Brazil; ${ }^{P}$ Psychiatrist, Department of Neurosciences and Behavior, Ribeirão Preto Medical School, University of São Paulo, Ribeirão Preto, Brazil; ${ }^{9}$ Professor, Department of Neurosciences and Behavior, Ribeirão Preto

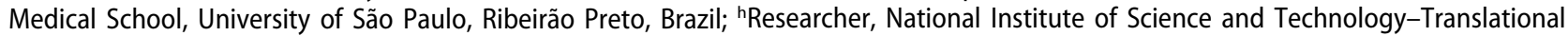
Medicine, Ribeirão Preto, Brazil
\end{abstract}

\begin{abstract}
Recently, the anti-addictive potential of ayahuasca, a dimethyltryptamine(DMT)- and $\beta$-carboline-rich hallucinogenic beverage traditionally used by indigenous groups of the Northwest Amazon and currently by syncretic churches worldwide, has received increased attention. To better evaluate this topic, we performed a systematic literature review using the PubMed database to find quantitative studies (using statistical analysis) that assessed the effects of ayahuasca or its components in drugrelated symptoms or disorders. We found five animal studies (using harmaline, harmine, or ayahuasca) and five observational studies of regular ayahuasca consumers. All animal studies showed improvement of biochemical or behavioral parameters related to drug-induced disorders. Of the five human studies, four reported significant reductions of dependence symptoms or substance use, while one did not report significant results. The mechanisms responsible for the anti-addictive properties of ayahuasca and its alkaloids are not clarified, apparently involving both peripheral MAO-A inhibition by the $\beta$-carbolines and central agonism of DMT at 5-HT2A receptors expressed in brain regions related to the regulation of mood and emotions. Although results are promising, controlled studies are needed to replicate these preliminary findings.
\end{abstract}

\section{ARTICLE HISTORY}

Received 27 January 2016

Revised 30 March 2016

Accepted 11 April 2016

\section{KEYWORDS}

Ayahuasca; dependence;

dimethyltryptamine;

hallucinogens; harmine
Ayahuasca is a hallucinogenic beverage traditionally used by Northwestern Amazonian tribes located in countries such as Brazil, Colombia, Ecuador, and Peru. It is usually prepared by the decoction of the stems of the Banisteriopsis caapi vine combined with the leaves of the Psychotria viridis bush (in Brazil, Peru, and parts of Ecuador) or of the liana Diplopterys cabrerana (in Colombia and Ecuador) (Luna 2011; Schultes 1986; Schultes and Hofmann 1992). At the beginning of the twentieth century, Northern Brazilians learned from indigenous and mestizo populations how to use ayahuasca and incorporated the ritual use of the beverage in syncretic religions such as the Santo Daime and the União do Vegetal (UDV) (Goulart 2011; Labate, Rose, and dos Santos 2009; Luna 2011). In the early 1990s, these religious groups started a slow and gradual expansion abroad, and are now present in South and North America, Europe, Asia, and Africa (Goulart 2011; Labate, Rose, and dos Santos 2009).
B. caapi is rich in $\beta$-carbolines such as harmine, tetrahydroharmine $(\mathrm{THH})$ and harmaline, which are reversible inhibitors of the enzyme monoamine oxidase-A (MAO-A) (dos Santos 2011; Riba 2003; Riba et al. 2003, 2015). The leaves of $P$. viridis and D. cabrerana contain DMT ( $N, N$-dimethyltryptamine), a tryptamine hallucinogen with a chemical structure similar to serotonin and which has agonist activity in several serotonergic receptors, especially in the 5- $\mathrm{HT}_{1 \mathrm{~A} / 2 \mathrm{~A} / 2 \mathrm{C}}$ receptors (dos Santos 2011; Riba 2003; Riba et al. 2003, 2015). DMT is inactive when administered in pure form and orally due to peripheral (gastrointestinal and liver) metabolism by MAO-A. In the case of ayahuasca, the $\beta$-carbolines reversibly inhibit MAO-A, thus preventing peripheral DMT degradation and enabling its absorption through systemic circulation and arrival at brain frontal and paralimbic $5-\mathrm{HT}_{1 \mathrm{~A} / 2 \mathrm{~A} / 2 \mathrm{C}}$ receptors, where it seems to

CONTACT Rafael G. dos Santos banisteria@gmail.com Departamento de Neurociências e Ciências do Comportamento, Faculdade de Medicina de Ribeirão Preto, Universidade de São Paulo, Hospital das Clínicas, Terceiro Andar, Av. Bandeirantes, Ribeirão Preto, São Paulo, Brazil; phone: + 55-163602-2703.

() 2016 Taylor \& Francis Group, LLC 
be responsible for the subjective and physiological effects of ayahuasca (dos Santos 2011; Riba 2003; Riba et al. 2003, 2006, 2015).

After oral intake, the psychoactive effects of ayahuasca start to occur in 30-40 minutes and reach their maximum intensity around 60-80 minutes after ingestion, gradually reducing their intensity and disappearing around 4-6 hours after administration (dos Santos 2011; dos Santos et al. 2011; Riba 2003; Riba et al. 2003, 2015). The main subjective effects observed are perceptual changes, altered thought content, intensification of emotions, introspection, positive mood, and sense of well-being (dos Santos 2011; dos Santos et al. 2011; Riba 2003; Riba et al. 2003, 2015). These subjective effects are associated with dose-dependent changes in brain electrical activity in regions such as the somatosensory, auditory, visual, and temporo-parietal association cortices (Riba 2003; Riba et al. 2004; Schenberg et al. 2015), as well as with alterations in brain activation and connectivity patterns in areas involved in emotion, perception, and memory processing, such as paralimbic structures and the Default Mode Network (DMN) (de Araujo et al. 2012; Palhano-Fontes et al. 2015; Riba 2003; Riba et al. 2006).

Acute administration of ayahuasca also induces moderate increases in blood pressure, heart rate, body temperature, pupil diameter, and in prolactin, cortisol, growth hormone, and natural killer cells' levels, as well as decreases of CD3 T, CD4 T, CD8 T, and CD19 B cells (dos Santos 2011; dos Santos et al. 2011, 2012;Riba 2003; Riba et al. 2003, 2015). However, these effects are temporary, and acute administration in a controlled environment to healthy individuals presents good tolerability. Adverse effects commonly related to ayahuasca intake are nausea, vomiting, and diarrhea (dos Santos 2011, 2013; dos Santos et al. 2011, 2012; Riba 2003; Riba et al. 2001). Long-term ritual consumption of ayahuasca is not associated with personality, cognitive or psychiatric problems (Barbosa et al. 2012; Bouso et al. 2012, 2015; dos Santos 2013), although alterations in cortical thickness were found in the posterior (thinning) and anterior (thickening) cingulate cortices (Bouso et al. 2015).

Anecdotal reports, animal models, observational studies, and preliminary clinical evidence suggest that ayahuasca and its alkaloids have anxiolytic, anti-depressive, and anti-addictive properties (dos Santos et al. 2007, 2016; Labate et al. 2010; Osório et al. 2015; Sanches et al. 2016). A recent open-label study reported fastacting and enduring anti-depressive effects associated with administration of a single ayahuasca dose to 17 patients with treatment-resistant major depressive disorder (Osório et al. 2015; Sanches et al. 2016).
Moreover, blood perfusion was significantly increased in the nucleus accumbens, subgenual area and insula, brain regions involved in mood and emotion processing (Sanches et al. 2016).

Anecdotal reports and limited observational evidence from psychotherapeutic centers around the world that use ayahuasca in the treatment of drug dependence suggest that the brew has beneficial effects (Barbosa et al. 2012; Bouso and Riba 2014; Labate et al. 2010; Mabit 2002; Miranda, Labigalini, and Tacla 1995). A few qualitative studies and observational investigations that did not perform statistical analysis also suggest potential therapeutic effects. One study made by Grob et al. (1996) recruited 30 volunteers- 15 members of the UDV for at least 10 years whose frequency of ayahuasca intake was at least twice a month, and 15 who had never tried ayahuasca-in Brazil to assess cognitive function and mental health (including drug consumption). All volunteers completed the Composite International Diagnostic Interview (CIDI) and performed a semi-structured interview to check their past and recent life stories. Regarding CIDI criteria, none of the UDV members had a psychiatric disorder, but five members fulfilled criteria for past alcohol abuse disorder according to DSM-III-R and ICD-10 definitions. Eleven members reported moderate to severe alcohol use prior to UDV membership, with eight reporting nicotine dependence, five describing previous episodes of excessive drinking and violent behavior, and four reporting cocaine and amphetamine use. Importantly, at the time of the study, all UDV volunteers showed a decrease in the use of drugs and complete alcohol abstinence.

A study performed by Halpern et al. (2008) in the United States recruited 32 Santo Daime members who consumed ayahuasca at least once a week (lifetime $269 \pm 314.7$ ceremonies; range $20-1300$ ) to assess their mental health, including drug consumption patterns, using the Structured Clinical Interview for DSM-IV Disorders (SCID) and an interview of past and current drug use. Eight participants reported previous alcohol abuse and five described past alcohol dependence, four reported cannabis abuse and three cannabis dependence, three described hallucinogen abuse, one sedative/hypnotic dependence, one cocaine abuse, and one stimulant abuse. After Santo Daime membership, most volunteers reported reductions in drug consumption or complete abstinence, with just one cannabis-dependent individual presenting partial remission and one volunteer who still abused cannabis.

Another study evaluated the pattern of substance use in Brazilian Santo Daime members using an interview based on the diagnostic criteria of the DSM-IV (Labate et al. 2014). Of 83 members evaluated, 41 showed a history of drug dependence, with $90 \%$ of them 
reporting recovery for the use of tobacco (99\%), alcohol (27\%), cocaine $(24 \%)$, crack (8\%), and MDMA, LSD, heroin, and solvents (5\%). Finally, a qualitative study aimed to generate empirically based hypotheses on the therapeutic mechanism of ayahuasca for the treatment of substance dependence by interviewing 14 individuals who underwent ayahuasca-assisted therapy for the treatment of drug dependence (mainly alcohol, cocaine, and crack) in diverse contexts in South America (Loizaga-Velder and Verres 2014). This study reported that, at the time of interview, 10 of the 14 interviewed patients were abstinent, three practiced controlled use, and one harm reduction. Nine of the 14 study participants reported reduced drug cravings after the use of ayahuasca, and three of the 14 reported attenuation of withdrawal symptoms.

Although the data described earlier suggest beneficial effects of ayahuasca in the treatment of drug dependence, these studies present important limitations, such as small sample sizes, heterogeneous methods, absence of a control group, their qualitative or observational design lacking statistical analysis, thus limiting the extrapolation of their results. Therefore, considering all of these aspects, the aim of this study was to develop a systematic review of the literature on the possible effects of ayahuasca in chemical dependence treatment.

\section{Material and methods}

The data for this systematic review were obtained according to the systematic reviews and meta-analysis guidelines from the PRISMA group (Moher et al. 2010).

\section{Data acquisition}

We attempted to identify all animal and human studies available for review until January 6, 2016, in which the anti-addictive effects of ayahuasca or of some of its isolated alkaloids (DMT, harmine, THH, and harmaline) were analyzed.

\section{Search strategy}

Electronic searches were performed using the PubMed (January 1, 1966-January 6, 2016) database. The following key words were used: ayahuasca OR dimethyltryptamine OR harmine OR tetrahydroharmine OR harmaline AND dependence or addiction. References were retrieved by searching the aforementioned electronic database and handsearching of reference lists of the identified literature. Chapters of specialized books were also included. All studies published in English up to January 6, 2016, were included.

\section{Eligibility criteria}

\section{Article type}

Only complete articles published in peer-reviewed scientific journals and book chapters, reporting quantitative studies that performed statistical analysis, were included. Qualitative studies, studies without statistical analysis, case reports, abstracts, letters, conference abstracts, comments, and editorials were excluded.

\section{Study design}

The review included (1) animal models of drug-induced disorders; (2) observational studies of ayahuasca consumers that assessed drug dependence symptoms with validated scales; and (3) clinical trials involving patients with a diagnosis of a drug abuse or dependence based on DSM criteria.

\section{Participants/sample}

Invertebrates (planarians), rodents (rat or mouse), healthy human volunteers (including ayahuasca consumers), and patients with a diagnosis of drug abuse or dependence based on DSM criteria.

\section{Interventions}

All designs evaluating the effect of ayahuasca or its alkaloids on drug-related symptoms or behaviors measures were included.

\section{Comparisons}

The main comparators considered were several experimental drugs with psychoactive properties (e.g., cocaine, amphetamines, ibogaine, and nicotine).

\section{Outcomes}

Studies investigating the effect of ayahuasca or its alkaloids on drug-related behavioral or biochemical parameters (animal studies) or symptoms (human studies) were included.

\section{Data extraction}

All studies were screened by two independent reviewers, with discrepancies resolved by a third reviewer. Names of authors, year of publication, study design (experimental, observational, clinical trial), characteristics of the participants (species, sample size), response criteria (anti-addictive effects), type of intervention (drug, dose), and type of outcome measure (animal model or psychometric instrument) were recorded for all included articles. The sample was divided into (1) animal and (2) human studies for the sake of clarity and to facilitate interpretation of results. 


\section{Results}

\section{Study selection}

A flow diagram illustrating the phases of the systematic review is presented in Figure 1.

The literature search yielded 93 separate references that were reviewed for abstract screening. Following this pass, eight potentially relevant references were identified (Aricioglu-Kartal, Kayir, and Uzbay 2003; Brierley and Davidson 2013; Doering-Silveira et al. 2005; Fábregas et al. 2010; Glick et al. 1994; OliveiraLima et al. 2015; Owaisat, Raffa, and Rawls 2012; Thomas et al. 2013). Two additional citations (da Silveira et al. 2005; Fernández et al. 2014) were added after handsearching the bibliography of the selected citations. Full-text reports of these 10 citations were obtained for a more detailed evaluation. Following detailed examination of the reports, all 10 citations were included. Included publications comprised five animal studies (Aricioglu-Kartal, Kayir, and Uzbay 2003; Brierley and Davidson 2013; Glick et al. 1994; Oliveira-Lima et al. 2015; Owaisat, Raffa, and Rawls 2012) and five human studies (all observational) (da Silveira et al. 2005; Doering-Silveira et al. 2005; Fábregas et al. 2010; Fernández et al. 2014; Thomas et al. 2013).

\section{Animal studies}

\section{Harmaline}

A study performed by Glick et al. (1994) in rats investigated the acute effects of harmaline on the self-administration of morphine and cocaine and reported that this alkaloid
(2.5-80 $\mathrm{mg} / \mathrm{kg}$, intraperitoneal) produced significant and dose-dependent acute reductions in both morphine and cocaine intake for at least a day after its administration. This may be significant in the case of cocaine, which does not have an officially approved pharmacological treatment.

\section{Harmine}

Aricioglu-Kartal, Kayir, and Uzbay (2003) investigated the effects of harmine on naloxone-precipitated withdrawal syndrome in morphine-dependent rats. Harmine $(5-10 \mathrm{mg} / \mathrm{kg}$, intraperitoneal) significantly attenuated the intensity of all signs of morphine withdrawal (wet-dog shakes, writhing, teeth chattering, defecation, diarrhea, tremor, and ptosis), except for jumping.

A study conducted by Brierley and Davidson (2013) in rat brain slices investigated the acute effects of harmine alone and in the presence of cocaine on dopamine efflux in the nucleus accumbens core and shell. Harmine $(300 \mathrm{nM})$ produced a significant increase in dopamine efflux in the accumbens shell (148 $\pm 8 \%$ of baseline values), as did cocaine (179 $\pm 20 \%)$, and the effects of both drugs combined were additive $(260 \pm 35 \%)$. However, contrary to cocaine, harmine did not produce significant increases on efflux in the accumbens core or on reuptake in both regions. This study suggests that harmine could act as a form of dopamine-releasing agonist or substitution therapy for cocaine dependence. Moreover, the effects of harmine were apparently mediated $5-\mathrm{HT}_{2 \mathrm{~A} / 2 \mathrm{C}}$ receptors and independent of MAO inhibition, since they were significantly reduced by a $5-\mathrm{HT}_{2 \mathrm{~A} / 2 \mathrm{C}}$ antagonist and a reversible MAO-A inhibitor did not significantly alter dopamine efflux.

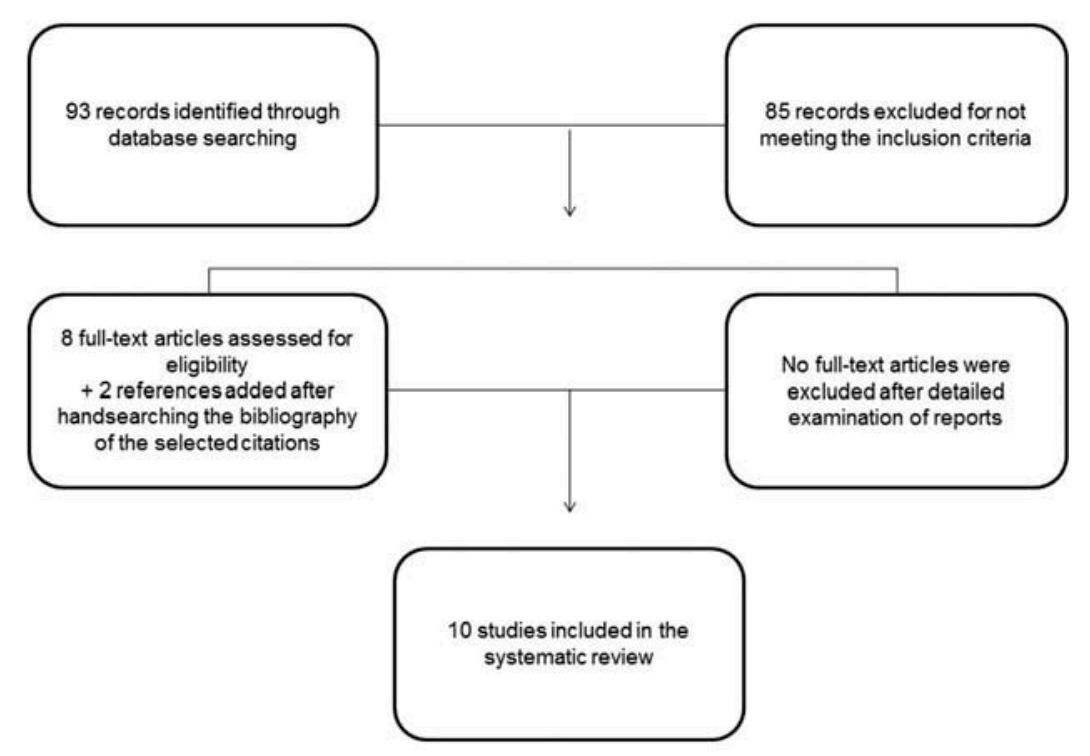

Figure 1. Flow diagram illustrating the different phases of the systematic review. 
Using an invertebrate (planarian) model to quantify "C-shape" responses, a characteristic behavior displayed by planarians, rats, and mice after administration of cocaine, amphetamines, nicotine, and glutamate, Owaisat, Raffa, and Rawls (2012) compared the effects of harmine against $N$-methyl-D-aspartate (NMDA), glutamate, cocaine, amphetamines (methamphetamine and mephedrone (4-methylmethcathinone), and nicotine. Harmine (0.01-10 $\mu \mathrm{M})$ did not produce C-shapes, but significantly inhibited C-shapes produced by all compounds, with a preferential efficacy against cocaine $>$ amphetamines $>$ nicotine. In the case of cocaine, these effects were apparently mediated by the glutamatergic system, since they were significantly attenuated after administration of a glutamate transporter inhibitor. Again, this may be relevant in the case of cocaine, which does not have an officially approved pharmacological treatment.

\section{Ayahuasca}

Oliveira-Lima et al. (2015) investigated the acute effects of ayahuasca on mice spontaneous locomotor activity and on ethanol-induced acute hyperlocomotion, locomotor sensitization (mice were re-exposed to the experimental apparatus seven days after the first ethanol injection), and reinstatement of ethanol-induced behavioral sensitization (ethanol administration every other day for 15 days, followed by eight consecutive days of saline or ayahuasca in liquid form, $100-300 \mathrm{mg} / \mathrm{kg}$ ). This animal model represents both the early behaviors associated with the initiation and development of ethanol dependence and the long-term effects such as the reinstatement of ethanol-induced sensitization. All ayahuasca doses (30-500 $\mathrm{mg} / \mathrm{kg}$, intraperitoneal) significantly reduced ethanol-induced sensitization without significantly modifying spontaneous locomotor activity. Moreover, the higher doses (300-500 $\mathrm{mg} / \mathrm{kg}$ ) significantly reduced ethanol-induced acute hyperlocomotion, and both doses of ayahuasca $(100-300 \mathrm{mg} / \mathrm{kg})$ significantly reduced the reinstatement of ethanol-induced sensitization.
The main information of the pre-clinical studies assessing the effects of ayahuasca and its alkaloids in behavioral and biochemical parameters associated with drug dependence is presented in Table 1 .

\section{Human studies}

\section{Ayahuasca}

In a retrospective study with adolescents in Brazil, da Silveira et al. (2005) assessed the mental health of 37 UDV members and 43 controls, and used the Drug Use Screening Inventory (DUSI) to assess lifetime (last-year and last-month) drug use. No significant results were found in lifetime substance consumption. However, in the same groups of adolescents, Doering-Silveira et al. (2005) reported significant differences regarding lastyear and last-month alcohol consumption, with UDV adolescents consuming less alcohol (last year: 46.3\%; last month: $32.5 \%$ ) than the control group (last year: 74.4\%; last month: $65.1 \%$ ).

In two studies with regular ayahuasca users in Brazil, Fábregas et al. (2010) assessed potential drug-abuserelated problems using the Addiction Severity Index (ASI) and an interview about their history of drug use. In the first study, jungle-based ayahuasca users $(\mathrm{n}=56)$ were compared to rural controls $(\mathrm{n}=56)$ and, in the second study, urban-based ayahuasca users $(\mathrm{n}=71)$ were compared to urban controls $(\mathrm{n}=59)$. Participants were evaluated again one year later in both studies. At baseline, the jungle-based ayahuasca group scored significantly lower than their controls in the ASI Medical Status, Alcohol Use, and Psychiatric Status subscales, and significantly higher in the Drug Use subscale (because ayahuasca use was also considered). These results were maintained in the follow-up, except for the Medical Status subscale. The urban-based ayahuasca group scored significantly lower than their controls in the Alcohol Use, Family/Social Relationships, and Psychiatric Status subscales at baseline, and significantly higher in the Employment/

Table 1. Effects of ayahuasca and its alkaloids in animal models of drug-related disorders.

\begin{tabular}{|c|c|c|c|c|c|}
\hline Models & Animals & Drug & Dose & Main results & References \\
\hline $\begin{array}{l}\text { Self-administration of morphine and } \\
\text { cocaine }\end{array}$ & Rats & Harmaline & $10-40 \mathrm{mg} / \mathrm{kg}$ & $\begin{array}{l}\text { Reductions of morphine and } \\
\text { cocaine intake }\end{array}$ & Glick et al. 1994 \\
\hline Morphine withdrawal syndrome & Rats & Harmine & $5-10 \mathrm{mg} / \mathrm{kg}$ & $\begin{array}{l}\text { Attenuation of morphine } \\
\text { withdrawal }\end{array}$ & $\begin{array}{l}\text { Aricioglu-Kartal, Kayir, and } \\
\text { Uzbay } 2003\end{array}$ \\
\hline $\begin{array}{l}\text { Dopamine efflux in the nucleus } \\
\text { accumbens }\end{array}$ & Rat (brain) & Harmine & $300 \mu \mathrm{M}$ & Increased dopamine efflux & Brierley and Davidson 2012 \\
\hline $\begin{array}{l}\text { "C-shape" responses induced by cocaine, } \\
\text { methamphetamine, mephedrone, } \\
\text { NMDA, and nicotine }\end{array}$ & Planarians & Harmine & $0.01-10 \mu \mathrm{M}$ & Inhibition of C-shapes & $\begin{array}{l}\text { Owaisat, Raffa, and Rawls } \\
2012\end{array}$ \\
\hline Ethanol-induced behavioral sensitization & Mice & Ayahuasca & $30-500 \mathrm{mg} / \mathrm{kg}$ & $\begin{array}{l}\text { Reduction of acute and } \\
\text { sensitized behavior }\end{array}$ & Oliveira-Lima et al. 2015 \\
\hline
\end{tabular}


Support Status and in the Drug Use subscales (like the jungle-based group, because ayahuasca use was also considered). At the follow-up, the ayahuasca group scored significantly lower in the Medical Status and higher in the Drug Use subscale (explained by ayahuasca use). An analysis of time-dependent changes in the two studies combined showed that the only increases (worsenings) were observed in the Family/ Social Relationships subscale in the urban-based ayahuasca group, while decreases (improvements) were shown for the Drug Use subscale in the jungle-based ayahuasca group. Moreover, except for cannabis, the ayahuasca jungle-based group did not report current use of illicit drugs, despite statistically significant differences in prior illicit drug use.

An observational study of ayahuasca-assisted therapy for problematic substance use and stress (the "Working with Addiction and Stress" retreat) was performed in a rural First Nations community in British Columbia, Canada, by Thomas et al. (2013). Twelve volunteers who had never taken ayahuasca before participated in a retreat which included four days of group counselling and two ayahuasca ceremonies. Drug use was assessed with the 4 Week Substance Use Scale (4WSUS) two and four weeks following the retreat and monthly thereafter for five months. Aggregated data from the means of all follow-ups using 4WSUS scores related to the substances used by $\geq 40 \%$ of the participants at baseline (tobacco, alcohol, cannabis, and cocaine) showed score decreases for all substances except cannabis, but significant reductions were observed only for cocaine. Moreover, significant improvements were observed in psychometric instruments assessing psychological and behavioral factors related to problematic substance use, such as hopefulness (Hope Scale, HS), empowerment (Empowerment Scale, ES), mindfulness (Philadelphia Mindfulness Scale, PHLMS), and quality of life (McGill Quality of Life survey, MQL).

Fernández et al. (2014) conducted a non-controlled study to examine the therapeutic effects of ayahuasca on drug dependence. Data were collected at a therapeutic institute in the Brazilian Amazonas State. The treatment included two ayahuasca session every week, and could last 3-9 months. Thirteen Spanish patients (8 men, mean age 35 years) participated in the study: nine cases of drug dependence (mainly related to heroin and cocaine), one of borderline personality disorder, and three subjects were searching ayahuasca for their personal growth. Regarding personality, after treatment, volunteers showed significant reductions in some subscales of the Temperament and Character Inventory-Revised (TCI-R) that measure personality traits that may be related to drug-related disorders, such as impulsivity.
The ayahuasca treatment was also associated with significant increases in subscales measuring selfdirectedness and responsibility. Psychopathology was also reduced, indicated by significant reductions in the scores of the Symptom Check-List-90-Revised (SCL-90-R). Neuropsychological improvements were also observed, with significant reductions in all subscales of the Frontal Systems Behavior Scale (FrSBe) and a significant increase in the "Resistance to Interference" measure of the Stroop Color and Word Test. Finally, beneficial effects were also observed regarding life attitudes and spirituality, with significant increases in the Purpose in Life Test (PLT) and in the Spiritual Orientation Inventory (SOI).

The main information of the quantitative studies assessing the effects of ayahuasca on drug dependence is presented in Table 2 .

\section{Discussion}

This systematic literature review of quantitative animal and human studies assessing the effects of ayahuasca and its alkaloids on behaviors and symptoms associated with drug-related disorders suggests that these substances seem to have properties that can help in the treatment of substance dependence or improvement of related disorders.

Harmine induced significant reductions in withdrawal symptoms in morphine-dependent rats (Aricioglu-Kartal, Kayir, and Uzbay 2003), harmaline significantly reduced morphine and cocaine intake in rats (Glick et al. 1994), and ayahuasca significantly reduced the behavioral effects produced by an experimental model of ethanol-induced sensitization in mice (Oliveira-Lima et al. 2015).

The mechanisms of action involved in these effects have not been completely elucidated, but appear to involve MAO inhibition and the glutamatergic, dopaminergic, and serotonergic system. For instance, harmine significantly reduced stimulant-induced behavior in planarians, and this effect was mediated by the glutamatergic system (Owaisat, Raffa, and Rawls 2012). Furthermore, harmine significantly increased dopamine efflux in the nucleus accumbens shell by a MAO-independent mechanism, probably involving the $5-\mathrm{HT}_{2 \mathrm{~A} / 2 \mathrm{C}}$ receptors (Brierley and Davidson 2013).

Several preclinical and clinical investigations suggest that striatal dopaminergic neurotransmission is deeply involved in the reinforcing properties of most psychoactive drugs, especially stimulants, and drug abuse and dependence (Nutt et al. 2015). Thus, the anti-addictive effects of harmine and harmaline could be mediated by the dopaminergic system. For instance, harmine and harmaline significantly increased L-DOPA-induced 
Table 2. Effects of ayahuasca in the treatment of drug dependence in humans.

\begin{tabular}{|c|c|c|c|}
\hline Sample & Scale & Main results & References \\
\hline $\begin{array}{l}37 \text { UDV adolescent members and } 43 \\
\text { controls }\end{array}$ & DUSI & Non-significant & da Silveira et al. 2005 \\
\hline $\begin{array}{l}41 \text { UDV adolescent members and } 43 \\
\text { controls }\end{array}$ & Drug use history & $\begin{array}{l}\text { nificantly lower last-year and last-month alcohol } \\
\text { nsumption }\end{array}$ & \\
\hline 127 ayahuasca users and 115 controls & & $\begin{array}{l}\text { mprovements in ASI subscales }{ }^{1} \text { and in } \\
\text { use (except for cannabis) }\end{array}$ & Fábregas et al. 2010 \\
\hline $\begin{array}{l}12 \text { ayahuasca naïve individuals seeking } \\
\text { treatment for problematic substance use }\end{array}$ & WSUS & $\begin{array}{l}\text { nd } \\
\text { havioral }\end{array}$ & Thomas \\
\hline $\begin{array}{l}9 \text { individuals seeking treatment for } \\
\text { problematic substance use }\end{array}$ & $\begin{array}{l}\text { TCl, SCL-90-R, FrSBe, } \\
\text { Stroop test, PLT, SOI }\end{array}$ & $\begin{array}{l}\text { Improvements in personality, }{ }^{3} \text { psychopathology, } \\
\text { cognition, }{ }^{5} \text { life attitudes, }{ }^{6} \text { and spirituality }{ }^{7}\end{array}$ & Fernández \\
\hline \multicolumn{4}{|c|}{$\begin{array}{l}\text { 4WSUS: } 4 \text { Week Substance Use Scale; FrSBe: Frontal System Behavior; PLT: Purpose in Life Test; SCL-90-R: Symptom Check-List-90-Revised; SOI: Spiritual } \\
\text { Orientation Inventory; TCI-R: Temperament and Character Inventory-Revised. } \\
{ }^{1} \text { Medical Status, Alcohol Use, Psychiatric Status, and Drug Use. } \\
{ }^{2} \text { Hopefulness (Hope Scale, HS), empowerment (Empowerment Scale, ES), mindfulness (Philadelphia Mindfulness Scale, PHLMS), and quality of life (McGill } \\
\text { Quality of Life survey, MQL). } \\
{ }^{3} \text { TCl-R Impulsiveness, Disorderliness, Anticipatory Worry, Shyness with Strangers, Responsibility, Purposefulness, Congruent Second Nature, and Self- } \\
\text { Directedness subscales. } \\
{ }^{4} \text { SCL-90-R Positive Symptoms, Total, Anxiety, and Obsessive-Compulsive subscales. } \\
{ }^{5} \text { FrSBe Dysfunction, Apathy, and Disinhibition subscales and Stroop's Resistance to Interference. } \\
{ }^{6} \text { PLT Transcendent Dimension, Meaning/Purpose in Life, Mission in Life, and Sacredness of Life subscales. }\end{array}$} \\
\hline
\end{tabular}

stereotypy in mice (Pimpinella and Palmery 1995), harmine dose-dependently increased dopamine levels in the rat brain (Iurlo et al. 2001), administration of $B$. caapi stem extract, harmine, and harmaline significantly increased dopamine release in rat striatal slices (Schwarz et al. 2003), and ayahuasca increased the dopamine utilization rate in the rat amygdala (de Castro-Neto et al. 2013). However, harmaline dose-dependently decreased dopamine levels in the mice inferior olivary nucleus, but not on the cerebellum (Mehta, Saravanan, and Mohanakumar 2003), and Oliveira-Lima et al. (2015) suggested that the reduction of ethanol-induced hyperlocomotion produced by ayahuasca could be related to decreased dopamine activity, since this ethanol-related behavior is associated with dopamine release in the nucleus accumbens.

Even considering a possible role of the dopaminergic (or glutamatergic) systems in the anti-addictive effects of harmine and harmaline, it must be considered that preclinical data do not always translate to humans. For instance, although preclinical evidence suggests that the $\beta$-carbolines have affinity for $5-\mathrm{HT}_{2 \mathrm{~A} / 2 \mathrm{C}}$ receptors (Glennon et al. 2000; Grella et al. 1998), human studies show that their psychoactive or hallucinogenic potential is questionable, and that the main mechanism of action of these compounds in ayahuasca seems to be the reversible inhibition of MAO-A (dos Santos 2011; Riba 2003; Riba et al. 2003, 2015). Nevertheless, a recent study in healthy volunteers suggested that the $\beta$-carbolines in ayahuasca could produce specific electroencephalographic alterations (Schenberg et al. 2015). Thus, the mechanisms of action of the $\beta$-carbolines have not been completely elucidated, and may involve changes in aminoacidergic and monoaminergic neurotransmission.

Regarding DMT, although some preclinical studies show that this tryptamine interacts with the dopaminergic system (Haubrich and Wang 1977; Jenner, Marsden, and Thanki 1980; Waldmeier and Maitre 1977), no human studies evaluated the effects of pure DMT in dopamine neurotransmission, and neuroimaging studies involving the administration of ayahuasca to healthy volunteers using single-photon emission computed tomography (SPECT) (Riba et al. 2006) and functional magnetic resonance imaging (fMRI) (de Araujo et al. 2012) did not find activation of the striatum (de Araujo et al. 2012; Riba et al. 2006).

However, a study involving the administration of psilocybin, a hallucinogenic tryptamine chemically and pharmacologically related to DMT that also acts as a $5-\mathrm{HT}_{2 \mathrm{~A}}$ receptor agonist and that has anti-addictive proprieties against alcohol (Bogenschutz et al. 2015) and tobacco dependence (Garcia-Romeu et al. 2014; Johnson et al. 2014) showed that this compound increased dopamine levels in the striatum (caudate and putamen nucleus) (Vollenweider et al. 1999). Moreover, a study with depressed patients using SPECT reported increased blood perfusion in the nucleus accumbens after ayahuasca administration (Sanches et al. 2016).

These results suggest that these hallucinogenic substances can act as modulators of the dopaminergic system, but further studies are needed to better investigate this topic, especially in clinical populations. Furthermore, considering that drug disorders are complex processes related to psychological, social, cultural, and biochemical 
factors and other associated psychopathologies, such as anxiety and depressive disorders, as well as neurodegenerative effects, other properties of ayahuasca and its alkaloids, such as anxiolytic and antidepressive effects (dos Santos et al. 2007, 2016; Osório et al. 2015; Sanches et al. 2016), as well as neuroprotective properties (Biradar, Joshi, and Tarak 2013; dos Santos et al. 2016) and effects on neurotrophic factors (dos Santos et al. 2016; Fortunato et al. 2009), should be better investigated.

Analysis of the data from the observational studies show that only one of the five studies included (da Silveira et al. 2005) did not present significant improvements in drug-related symptoms or disorders. Considering the studies with significant results, all reported improvements, such as decreased drug use, reduced withdrawal symptoms, and cases of completely recovery from drug dependence. Interestingly, significant results were more expressive regarding alcohol and cocaine use, which is similar to the results observed in the preclinical data evaluated in the systematic review.

However, in the case of humans, the apparent effectiveness of ayahuasca in handling symptoms of drug withdrawal, abuse, or dependence could be associated not only with its biochemical mechanisms of action, but also with religious and psychological aspects, since ayahuasca is usually consumed in a ritual context and may even involve membership in organized religious institutions or groups, such as the Santo Daime and the UDV (Goulart 2011; Labate et al. 2010; Labate, Rose, and dos Santos 2009; Luna 2011). In these groups, the use of illicit drugs is usually discouraged or prohibited, and the fact that ayahuasca is inserted in a religious context seems to ensure some protection against possible drug use (Barbosa et al. 2012; Doering-Silveira et al. 2005; Goulart 2011; Grob et al. 1996; Halpern et al. 2008; Labate et al. 2010; Labate, Rose, and dos Santos 2009). Indeed, participation in religious groups may improve quality of life and well-being (Panzini et al. 2007).

In the study by Fernández et al. (2014), a significant increase in spirituality was observed, and reports from the participants suggest that the experiences during the psychedelic effects generated by the beverage appear to help them to better understand their problems, in the resolution of traumas, by encouraging them to make better decisions, improving their social relations, and helping them developing more responsibility, motivation, and purpose in life (Bouso et al. 2012; da Silveira et al. 2005; Doering-Silveira et al. 2005; Grob et al. 1996; Halpern et al. 2008; Thomas et al. 2013). Interestingly, psilocybin administration is associated with mystical-type experiences and sustained well-being, and these effects are apparently related to recovery from drug dependence (Garcia-Romeu et al. 2014; Griffiths et al. 2011). Moreover, religious use of peyote-a cactus containing the phenethylamine psychedelic alkaloid mescaline, which has hallucinogenic effects similar to those of ayahuasca and psilocybin and also binds to and activates the serotonin $5-\mathrm{HT}_{2 \mathrm{~A}}$ receptor-by groups such as the Native American Church is associated with reduced alcohol abuse and dependence, and similar to ritual ayahuasca use, there is no evidence of psychological or cognitive deficits associated with this practice (Calabrese 1997; Halpern et al. 2005).

Finally, from a psychological perspective, not only the mystical experiences, but also the insights, cognitive and emotional effects that are experienced in ayahuasca-induced modified states of consciousness have therapeutic potential for the recovery from addiction (see Loizaga-Velder and Verres 2014). From a neurochemical perspective, the therapeutic properties described could also be related to intensification of brain activity in frontal and paralimbic neural pathways involved in emotional and memory processing (de Araujo et al. 2012; Riba et al. 2006), or to decreased activity in the cortical areas associated with introspection and self- consciousness, such as the DMN (Bouso et al. 2015; Palhano-Fontes et al. 2015).

Although most of the results suggest that ayahuasca or its alkaloids have potential use in the treatment of drug abuse and dependence, the human studies reviewed have important limitations, including the small sample sizes, their observational design, and the assessment of experienced users of ayahuasca. This last factor limits the sample to people that are already adapted to the effects of ayahuasca, thus limiting the extrapolation of the results and possibly excluding those consumers who could have experienced some adverse effect and never consumed ayahuasca again. Moreover, the fact that most ayahuasca use happens in a ritual context makes it difficult to establish if the observed health improvements are related to drug effects, to the religious environment and culture, or the combination of both factors.

Considering these issues, more clinical and controlled studies are needed to assess whether ayahuasca is actually effective in the treatment of drug dependence.

\section{Funding}

This research received financial support from Fundação de Amparo à Pesquisa do Estado de São Paulo, Brazil (Fapesp Process No.1502848-2). AAA is a Fellow of the Programa Institucional de Bolsas de Iniciação Científica (PIBIC/CNPq), Brazil. RGS is a Fellow of the Programa Nacional de PósDoutorado, Brazil (PNPD/CAPES). JASC and JECH received a CNPq (Brazil) Productivity Fellowship Award. The sponsors had no role in the study design, data analysis, data interpretation, or writing of the report. All authors had full access to all of the data and had final responsibility for the decision to submit this article for publication. 


\section{ORCID}

Rafael G. dos Santos (D) http://orcid.org/0000-0003-2388-4745

\section{References}

Aricioglu-Kartal, F., H. Kayir, and I. T. Uzbay. 2003. Effects of harman and harmine on naloxone-precipitated withdrawal syndrome in morphine-dependent rats. Life Science 73 (18):2363-71. doi:10.1016/S0024-3205(03) 00647-7.

Barbosa, P. C., S. Mizumoto, M. P. Bogenschutz, and R. J. Strassman. 2012. Health status of ayahuasca users. Drug Testing Analysis 4 (7-8):601-09. doi:10.1002/dta.1383.

Biradar, S. M., H. Joshi, and K. C. Tarak. 2013. Cerebroprotective effect of isolated harmine alkaloids extracts of seeds of Peganum harmala L. on sodium nitrite-induced hypoxia and ethanol-induced neurodegeneration in young mice. Pakistan Journal of Biological Sciences 16 (23):1687-97. doi:10.3923/pjbs.2013.1687.1697.

Bogenschutz, M. P., A. A. Forcehimes, J. A. Pommy, C. E. Wilcox, P. C. R. Barbosa, and R. J. Strassman. 2015. Psilocybin-assisted treatment for alcohol dependence: A proof-of-concept study. Journal of Psychopharmacology 29 (3):289-99. doi:10.1177/0269881114565144.

Bouso, J. C., D. González, S. Fondevila, M. Cutchet, X. Fernández, P. C. R. Barbosa, M. A. Alcázar-Córcoles, W. S. Araújo, M. J. Barbanoj, J. M. Fábregas, and J. Riba. 2012. Personality, psychopathology, life attitudes and neuropsychological performance among ritual users of Ayahuasca: A longitudinal study. PLoS One 7 (8):e42421. doi:10.1371/ journal.pone.0042421.

Bouso, J. C., F. Palhano-Fontes, A. Rodríguez-Fornells, S. Ribeiro, R. Sanches, J. A. Crippa, J. E. Hallak, D. B. de Araujo, and J. Riba. 2015. Long-term use of psychedelic drugs is associated with differences in brain structure and persona in humans. European Neuropsychopharmacology 25 (4):483-92. doi:10.1016/j.euroneuro.2015.01.008.

Bouso, J. C., and J. Riba. 2014. Ayahuasca and the treatment of drug addiction. In The therapeutic use of ayahuasca, eds. B. C. Labate and C. Cavnar. Berlin: Springer-Verlag.

Brierley, D. I., and C. Davidson. 2012. Developments in harmine pharmacology: Implications for ayahuasca use and drug-dependence treatment. Progress in Neuropsychopharmacology \& Biological Psychiatry 39 (2):263-72. doi:10.1016/j.pnpbp.2012.06.001.

Brierley, D. I., and C. Davidson. 2013. Harmine augments electrically evoked dopamine efflux in the nucleus accumbens shell. Journal of Psychopharmacology 27 (1):98-108. doi:10.1177/0269881112463125.

Calabrese, J. D. 1997. Spiritual healing and human development in the Native American church: Toward a cultural psychiatry of peyote. Psychoanalytic Review 84 (2):237-55. da Silveira, D. X., C. S. Grob, M. D. de Rios, E. Lopez, L. K. Alonso, C. Tacla, and E. Doering- Silveira. 2005. Ayahuasca in adolescence: A preliminary psychiatric assessment. Journal of Psychoactive Drugs 37 (2):129-33. doi:10.1080/02791072.2005.10399792.

de Araujo, D. B., S. Ribeiro, G. A. Cecchi, F. M. Carvalho, T. A. Sanchez, J. P. Pinto, B. S. de Martinis, J. A. Crippa, J. E. C. Hallak, and A. C. Santos. 2012. Seeing with the eyes shut: Neural basis of enhanced imagery following ayahuasca ingestion. Human Brain Mapping 33 (11):255060. doi:10.1002/hbm.21381.

de Castro-Neto, E. F., R. H. da Cunha, D. X. da Silveira, M. Yonamine, T. L. Gouveia, E. A. Cavalheiro, D. Amado, and M. G. Naffah-Mazzacoratti. 2013. Changes in aminoacidergic and monoaminergic neurotransmission in the hippocampus and amygdala of rats after ayahuasca ingestion. World Journal of Biological Chemistry 4 (4):141-47.

Doering-Silveira, E., C. S. Grob, M. D. de Rios, E. Lopez, L. K. Alonso, C. Tacla, and D. X. da Silveira. 2005. Report on psychoactive drug use among adolescents using ayahuasca within a religious context. Journal of Psychoactive Drugs 37 (2):141-44. doi:10.1080/02791072.2005.10399794.

dos Santos, R. G. 2011. Ayahuasca: Physiological and subjective effects, comparison with d-amphetamine, and repeated dose assessment. Doctoral thesis, Universitat Autònoma de Barcelona, Barcelona, Spain. https://www. educacion.gob.es/teseo/mostrarRef.do?ref $=959049$ (accessed January 10, 2016).

dos Santos, R. G. 2013. Safety and side effects of ayahuasca in humans: An overview focusing on developmental toxicology. Journal of Psychoactive Drugs 45 (1):68-78. doi:10.1080/02791072.2013.763564.

dos Santos, R. G., E. Grasa, M. Valle, M. R. Ballester, J. C. Bouso, J. F. Nomdedéu, R. Homs, M. J. Barbanoj, and J. Riba. 2012. Pharmacology of ayahuasca administered in two repeated doses. Psychopharmacology 219 (4):1039-53. doi:10.1007/s00213-011-2434-x.

dos Santos, R. G., J. Landeira-Fernandez, R. J. Strassman, V. Motta, and A. P. Cruz. 2007. Effects of ayahuasca on psychometric measures of anxiety, panic-like and hopelessness in Santo Daime members. Journal of Ethnopharmacology $112 \quad$ (3):507-13. doi:10.1016/j. jep.2007.04.012.

dos Santos, R. G., F. L. Osório, J. A. Crippa, and J. E. Hallak. 2016. Antidepressive and anxiolytic effects of ayahuasca: A systematic literature review of animal and human studies. Revista Brasileira de Psiquiatria 38:65-72. doi:10.1590/ 1516-4446-2015-1701.

dos Santos, R. G., M. Valle, J. C. Bouso, J. F. Nomdedéu, J. RodrÍguez-Espinosa, E. H. McIlhenny, S. A. Barker, M. J. Barbanoj, and J. Riba. 2011. Autonomic, neuroendocrine, and immunological effects of ayahuasca: A comparative study with $d$-amphetamine. Journal of Clinical

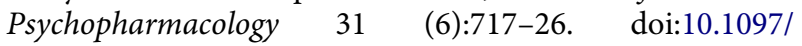
JCP.0b013e31823607f6.

Fábregas, J. M., D. González, S. Fondevila, M. Cutchet, X. Fernández, P. C. Barbosa, M. A. Alcázar-Córcoles, M. J. Barbanoj, J. Riba, and J. C. Bouso. 2010. Assessment of addiction severity among ritual users of ayahuasca. Drug and Alcohol Dependence 111 (3):257-61. doi:10.1016/j. drugalcdep.2010.03.024.

Fernández, X., R. G. dos Santos, M. Cutchet, S. Fondevila, D. González, M. A. Alcázar, J. Riba, J. C. Bouso, and J. M. Fábregas. 2014. Assessment of the psychotherapeutic effects of ritual ayahuasca use on drug dependency: A pilot study. In The therapeutic use of ayahuasca, eds. B. C. Labate and C. Cavnar. Berlin: Springer.

Fortunato, J. J., G. Z. Réus, T. R. Kirsch, R. B. Stringari, L. Stertz, F. Kapczinski, J. P. Pinto, J. E. Hallak, A. W. Zuardi, J. A. Crippa, and J. Quevedo. 2009. Acute harmine 
administration induces antidepressive-like effects and increases BDNF levels in the rat hippocampus. Progress in Neuropsychopharmacology \& Biological Psychiatry 33 (8):1425-30. doi:10.1016/j.pnpbp.2009.07.021.

Garcia-Romeu, A., R. Roland, R. R. Griffiths, and M. W. Johnson. 2014. Psilocybin-occasioned mystical experiences in the treatment of tobacco addiction. Current Drug Abuse Reviews 7 (3):157-64. doi:10.2174/1874473708666150107121331.

Glennon, R. A., M. Dukat, B. Grella, S. Hong, L. Costantino, M. Teitler, C. Smith, C. Egan, K. Davis, and M. V. Mattson. 2000. Binding of $\beta$-carbolines and related agents at serotonin $\left(5-\mathrm{HT}_{2}\right.$ and $\left.5-\mathrm{HT}_{1 \mathrm{~A}}\right)$, dopamine $\left(\mathrm{D}_{2}\right)$ and benzodiazepine receptors. Drug and Alcohol Dependence 60 (2):121-32. doi:10.1016/S0376-8716(99)00148-9.

Glick, S. D., M. E. Kuehne, J. Raucci, T. E. Wilson, D. Larson, R. W. Keller Jr., and J. N. Carlson. 1994. Effects of iboga alkaloids on morphine and cocaine self-administration in rats: Relationship to tremorigenic effects and to effects on dopamine release in nucleus accumbens and striatum. Brain Research 657 (1-2):14-22. doi:10.1016/0006-8993 (94)90948-2.

Goulart, S. L. 2011. The notion of cure in the Brazilian ayahuasca religions. In The ethnopharmacology of ayahuasca, ed. R. G. dos Santos. Trivandrum, India: Transworld Research Network.

Grella, B., M. Dukat, R. Young, M. Teitler, K. Herrick-Davis, C. B. Gauthier, and R. A. Glennon. 1998. Investigation of hallucinogenic and related $\beta$-carbolines. Drug and Alcohol Dependence 50 (2):99-107. doi:10.1016/S0376-8716(97) 00163-4.

Griffiths, R. R., M. W. Johnson, W. A. Richards, B. D. Richards, U. McCann, and R. Jesse. 2011. Psilocybin occasioned mystical-type experiences: Immediate and persisting dose-related effects. Psychopharmacology 218 (4):649-65. doi:10.1007/s00213-011-2358-5.

Grob, C. S., D. J. McKenna, J. C. Callaway, G. S. Brito, E. S. Neves, G. Oberlaender, O. L. Saide, E. Labigalini, C. Tacla, C. T. Miranda, R. J. Strassman, and K. B. Boone. 1996. Human psychopharmacology of hoasca, a plant hallucinogen used in ritual context in Brazil. The Journal of Nervous and Mental Disease 184 (2):86-94. doi:10.1097/00005053199602000-00004.

Halpern, J. H., A. R. Sherwood, J. I. Hudson, D. YurgelunTodd, and H. G. Pope Jr. 2005. Psychological and cognitive effects of long-term peyote use among Native Americans. Biological Psychiatry 58 (8):624-31. doi:10.1016/j. biopsych.2005.06.038.

Halpern, J. H., A. R. Sherwood, T. Passie, K. C. Blackwell, and A. J. Ruttenber. 2008. Evidence of health and safety in American members of a religion who use a hallucinogenic sacrament. Medical Science Monitor 14 (8):SR15-22.

Haubrich, D. R., and P. F. L. Wang. 1977. N,N-dimethyltryptamine lowers rat brain acetylcholine and dopamine. Brain Research 131 (1):158-1. doi:10.1016/0006-8993(77)90036-1.

Iurlo, M., M. G. Leone, B. Schilstrom, L. Linnér, G. G. Nomikos, P. Hertel, B. Silvestrini, and T. H. Svensson. 2001. Effects of harmine on dopamine output and metabolism in rat striatum: Role of monoamine oxidase-A inhibition. Psychopharmacology $159 \quad$ (1):98-104. doi:10.1007/s002130100879.

Jenner, P., C. D. Marsden, and C. M. Thanki. 1980. Behavioural changes induced by $N, N$-dimethyltryptamine in rodents. British Journal of Pharmacology 69 (1):69-80. doi:10.1111/bph.1980.69.issue-1.

Johnson, M. W., A. Garcia-Romeu, M. P. Cosimano, and R. R. Griffiths. 2014. Pilot study of the $5-\mathrm{HT}_{2 \mathrm{~A}} \mathrm{R}$ agonist psilocybin in the treatment of tobacco addiction. Journal of Psychopharmacology 28 (11):983-92. doi:10.1177/ 0269881114548296.

Labate, B. C., R. G. dos Santos, B. Anderson, M. Mercante, and P. C. R. Barbosa. 2010. The treatment and handling of substance dependence with ayahuasca: Reflections on current and future research. In Ayahuasca, ritual and religion, eds. B. C. Labate and E. MacRae. London: Equinox.

Labate, B. C., R. G. dos Santos, R. Strassman, B. T. Anderson, and S. Mizumoto. 2014. Effect of Santo Daime membership on substance dependence. In The therapeutic use of Ayahuasca, eds. B. C. Labate and C. Cavnar. Berlin: Springer.

Labate, B. C., I. S. Rose, and R. G. dos Santos. 2009. Ayahuasca religions: A comprehensive bibliography and critical essays. Santa Cruz, CA: Multidisciplinary Association for Psychedelic Studies.

Loizaga-Velder, A., and R. Verres. 2014. Therapeutic effects of ritual ayahuasca use in the treatment of substance dependence: Qualitative results. Journal of Psychoactive Drugs 46 (1):63-72. doi:10.1080/02791072.2013.873157.

Luna, L. E. 2011. Indigenous and mestizo use of ayahuasca: An overview. In The ethnopharmacology of ayahuasca, ed. R. G. dos Santos. Trivandrum, India: Transworld Research Network.

Mabit, J. 2002. Blending traditions: Using indigenous medicinal knowledge to treat drug addiction. Bulletin of the Multidisciplinary Association of Psychedelic Studies 12 (2):25-32. http://maps.org/newsletters/v12n2/12225mab. pdf (accessed January 10, 2015).

Mehta, H., K. S. Saravanan, and K. P. Mohanakumar. 2003. Serotonin synthesis inhibition in olivo-cerebellar system attenuates harmaline-induced tremor in Swiss albino mice. Behavioural Brain Research 145 (1-2):31-36. doi:10.1016/S0166-4328(03)00094-9.

Miranda, C. T., E. Labigalini Jr., and C. Tacla. 1995. Alternative religion and outcome of alcohol dependence in Brazil. Addiction 90 (6):847. doi:10.1111/add.1995.90. issue-6.

Moher, D., A. Liberati, J. Tetzlaff, and D. G. Altman. 2010. The PRISMA Group. Preferred reporting items for systematic reviews and meta-analyses: The PRISMA statement. International Journal of Surgery 8 (5):336-41. doi:10.1016/j.ijsu.2010.02.007.

Nutt, D. J., A. Lingford-Hughes, D. Erritzoe, and P. R. A. Stokes. 2015. The dopamine theory of addiction: 40 years of highs and lows. Nature Reviews Neuroscience 16 (5):305-12. doi:10.1038/nrn3939.

Oliveira-Lima, A. J., R. Santos, A. W. Hollais, C. A. GerardiJunior, M. A. Baldaia, R. Wuo- Silva, T. S. Yokoyama, J. L. Costa, E. L. Malpezzi-Marinho, P. C. R. Barbosa, L. F. Berro, R. Frussa-Filho, and E. A. Marinho. 2015. Effects of ayahuasca on the development of ethanol-induced behavioral sensitization and on a post-sensitization treatment in mice. Physiology \& Behavior 142:28-36. doi:10.1016/j. physbeh.2015.01.032.

Osório, F. L., R. F. Sanches, L. R. Macedo, R. G. dos Santos, J. P. Maia-de-Oliveira, L. Wichert-Ana, D. B. de Araujo, J. 
Riba, J. A. Crippa, and J. E. Hallak. 2015. Antidepressant effects of a single dose of ayahuasca in patients with recurrent depression: A preliminary report. Revista Brasileira de Psiquiatria 37 (1):13-20. doi:10.1590/ 1516-4446-2014-1496.

Owaisat, S., R. B. Raffa, and S. M. Rawls. 2012. In vivo comparison of harmine efficacy against psychostimulants: Preferential inhibition of the cocaine response through a glutamatergic mechanism. Neuroscience Letters 525 (1): 12-16. doi:10.1016/j.neulet.2012.07.052.

Palhano-Fontes, F., K. C. Andrade, L. F. Tofoli, A. C. Santos, J. A. Crippa, J. E. Hallak, S. Ribeiro, and D. B. de Araujo. 2015. The psychedelic state induced by ayahuasca modulates the activity and connectivity of the default mode network. PLoS One 10 (2):e0118143. doi:10.1371/journal. pone.0118143.

Panzini, R. G., N. S. da Rocha, D. R. Bandeira, and M. P. A. Fleck. 2007. Quality of life and spirituality. Revista de Psiquiatria Clínica 34 (supl 1):105-15. doi:10.1590/S010160832007000700014.

Pimpinella, G., and M. Palmery. 1995. Interaction of $\beta$-carbolines with central dopaminergic transmission in mice: Structureactivity relationships. Neuroscience Letters 189 (2):121-24. doi:10.1016/0304-3940(95)11469-D.

Riba, J. 2003. Human pharmacology of ayahuasca. Doctoral thesis, Universitat Autònoma de Barcelona, Barcelona, Spain. http://www.tdx.cesca.es/TDX-0701104-165104/ (accessed January 10, 2016).

Riba, J., H. E. McIlhenny, J. C. Bouso, and S. A. Barker. 2015. Metabolism and urinary disposition of N,N-dimethyltryptamine after oral and smoked administration: A comparative study. Drug Testing and Analysis 7 (5):401-06. doi:10.1002/dta.1685.

Riba, J., A. Rodríguez-Fornells, G. Urbano, A. Morte, R. Antonijoan, M. Montero, J. C. Callaway, and M. J. Barbanoj. 2001. Subjective effects and tolerability of the South American psychoactive beverage ayahuasca in healthy volunteers. Psychopharmacology 154 (1):85-95. doi:10.1007/s002130000606.

Riba, J., S. Romero, E. Grasa, E. Mena, I. Carrió, and M. J. Barbanoj. 2006. Increased frontal and paralimbic activation following ayahuasca, the pan-Amazonian inebriant. Psychopharmacology 186 (1):93-98. doi:10.1007/s00213006-0358-7.

Riba, J., M. Valle, G. Urbano, M. Yritia, A. Morte, and M. J. Barbanoj. 2003. Human pharmacology of ayahuasca: Subjective and cardiovascular effects, monoamine metabolite excretion, and pharmacokinetics. Journal of
Pharmacology and Experimental Therapeutics 306 (1): 73-83. doi:10.1124/jpet.103.049882.

Riba, J., M. Valle, G. Urbano, M. Yritia, A. Morte, and M. J. Barbanoj. 2004. Effects of the South American psychoactive beverage ayahuasca on regional brain electrical activity in humans: A functional neuroimaging study using lowresolution electromagnetic tomography. Neuropsychobiology 50 (1):89-101. doi:10.1159/000077946.

Sanches, R. F., F. L. Osório, R. G. dos Santos, L. R. H. Macedo, J. P. Maia-de-Oliveira, L. Wichert-Ana, D. B. de Araujo, J. Riba, J. A. S. Crippa, and J. E. C. Hallak. 2016. Antidepressant effects of a single dose of ayahuasca in patients with recurrent depression: A SPECT study. Journal of Clinical Psychopharmacology 36 (1):77-81. doi:10.1097/JCP.0000000000000436.

Schenberg, E. E., J. F. Alexandre, R. Filev, A. M. Cravo, J. R. Sato, S. D. Muthukumaraswamy, M. Yonamine, M. Waguespack, I. Lomnicka, S. A. Barker, and D. X. da Silveira. 2015. Acute biphasic effects of ayahuasca. PLoS One 10 (9):e0137202. doi:10.1371/journal.pone.0137202.

Schultes, R. E. 1986. El desarrollo histórico de la identificación de las malpigiáceas empleadas como alucinógenos [The historical development of the identification of malpighiaceous used as hallucinogens]. América Indígena 46 (1):9-47.

Schultes, R. E., and A. Hofmann. 1992. Plants of the gods: Their sacred, healing, and hallucinogenic powers. Rochester, NY: Healing Arts Press.

Schwarz, M. J., P. J. Houghton, S. Rose, P. Jenner, and A. D. Lees. 2003. Activities of extract and constituents of Banisteriopsis caapi relevant to Parkinsonism. Pharmacology, Biochemistry \& Behavior 75 (3):627-33. doi:10.1016/S0091-3057(03)00129-1.

Thomas, G., P. Lucas, N. R. Capler, K. W. Tupper, and G. Martin. 2013. Ayahuasca-assisted therapy for addiction: Results from a preliminary observational study in Canada. Current Drug Abuse Reviews 6 (1):30-42. doi:10.2174/15733998113099990003.

Vollenweider, F. X., P. Vontobel, D. Hell, and K. L. Leenders. 1999. 5-HT Modulation of dopamine release in basal ganglia in psilocybin-induced psychosis in man: A PET study with $\left[{ }^{11} \mathrm{C}\right]$ raclopride. Neuropsychopharmacology 20 (5):424-33. doi:10.1016/S0893-133X(98)00108-0.

Waldmeier, P. C., and L. Maitre. 1977. Neurochemical investigations of the interaction of $N, N$-dimethyltryptamine with dopaminergic system in rat brain. Psychopharmacology 52 (2):137-44. doi:10.1007/BF00439100. 